\title{
Synthesis and evaluation of fosfomycin group end-capped packing materials for hydrophilic interaction liquid chromatography
}

\author{
Zhihua Songa,*, Jinhua $\mathrm{Li}^{\mathrm{b}}$, Wenhui Lu ${ }^{\mathrm{c}}$, Bowei $\mathrm{Li}^{\mathrm{b}}$, Jinqiu Liu ${ }^{\mathrm{a}}$, Yaqi Wang ${ }^{\mathrm{a}}$, \\ Yumeng Wang ${ }^{\mathrm{a}}$, Zhong Zhang ${ }^{\mathrm{d}}$, Lingxin Chen ${ }^{\mathrm{b}, *}$ \\ a School of Pharmacy, Collaborative Innovation Center of Advanced Drug Delivery System and Biotech Drugs in Universities of Shandong, Key Laboratory of \\ Molecular Pharmacology and Drug Evaluation (Yantai University), Ministry of Education, Yantai University, Yantai 264005, PR China \\ ${ }^{\mathrm{b}}$ CAS Key Laboratory of Coastal Environmental Processes and Ecological Remediation, Research Center for Coastal Environmental Engineering and \\ Technology, Yantai Institute of Coastal Zone Research, Chinese Academy of Sciences, Yantai 264003, PR China \\ ' School of Light Industry and Engineering, Qilu University of Technology (Shandong Academy of Sciences), Jinan 250353, PR China \\ d Shaanxi Engineering Laboratory for Food Green Processing and Safety Control, College of Food Engineering and Nutritional Science, Shaanxi Normal \\ University, Xi'an, Shaanxi, PR China
}

\section{A R T I C L E I N F O}

\section{Article history:}

Received 6 April 2021

Revised 30 August 2021

Accepted 31 August 2021

Available online 4 September 2021

\section{Keywords:}

Fosfomycin

Zirconia coated silica materials

Hydrophilic interaction liquid

chromatography

Chromatographic stationary phases

Alkaloids and benzoic acids

\begin{abstract}
A B S T R A C T
Hydrophilic interaction liquid chromatography (HILIC) plays an important role in the analysis of compounds having high polarity. In this study, fosfomycin (F) was chosen as a new end-capping reagent, owing to the facile hydrolysis reaction of its epoxy group. Zirconia coated silica $\left(\mathrm{ZrO}_{2} / \mathrm{SiO}_{2}\right)$ materials having good chemical and physical stability were prepared. D-glucose-6-phosphate $(G)$ and D-fructose1,6bisphosphate (FDP) were modified onto the inner and outer surfaces of the $\mathrm{ZrO}_{2} / \mathrm{SiO}_{2}$ microbeads. The new end-capping reagent $(F)$ was then bonded onto the surface of the modified material through Lewis acid-base interactions. The properties (morphology, $\mathrm{Zr}$ content, pore size, pore volume, and carbon content) of the stationary phases (SPs) were characterized. Finally, the resulting end-capped SPs were employed to separate alkaloids and benzoic acids. Multiple interactions, including HILIC, electrostatic repulsion, ion exchange and hydrogen bonding, contributed to the retention of the analytes on the SPs. On the F-FDP- $\mathrm{ZrO}_{2} / \mathrm{SiO}_{2}$ column, a theoretical plate number of 31,700 plates $/ \mathrm{m}$ and an asymmetry factor of 1.63 were achieved for berberine, exhibiting good chromatographic performance. Furthermore, the FDP$\mathrm{ZrO}_{2} / \mathrm{SiO}_{2}$ column showed good acid-base stability and good potential for the analysis of benzoic acid in Sprite and ginsenoside separations. Thus, the results indicated the significant potential of using $\mathrm{F}$ as an end-capping reagent.
\end{abstract}

(C) 2021 Elsevier B.V. All rights reserved.

\section{Introduction}

High performance liquid chromatography (HPLC) is one of the most widely used and effective tools in various research fields such as food analysis [1,2], pharmaceutical analysis [3-5], biological sample analysis [6], and environmental science [7,8]. Chromatographic columns are the core of HPLC, with chromatographic stationary phases (SPs) being their key component. Thus, the design, synthesis, and evaluation of novel SPs exhibiting good performance have garnered significant research interest [9-12]. Recently, metal oxide coated silica materials (such as $\mathrm{Al}_{2} \mathrm{O}_{3} / \mathrm{SiO}_{2}$ [13], $\mathrm{TiO}_{2} / \mathrm{SiO}_{2}$ SPs [14], and $\mathrm{ZrO}_{2} / \mathrm{SiO}_{2}$ microbeads [15]) have exhibited considerable application potential in HPLC and sample preparation [16]. In particular, $\mathrm{ZrO}_{2}$ and $\mathrm{ZrO}_{2} / \mathrm{SiO}_{2}$ based materials

\footnotetext{
* Corresponding authors.

E-mail addresses: zhihuasong08@yeah.net (Z. Song), lxchen@yic.ac.cn (L. Chen).
}

have received considerable attention as SPs for HPLC owing to their significant mechanical, chemical $(1<\mathrm{pH}<14)$, and thermal $\left(\geq 200{ }^{\circ} \mathrm{C}\right.$ ) stabilities $[17,18]$. Moreover, $\mathrm{ZrO}_{2} / \mathrm{SiO}_{2}$ based SPs show substantial potential for the separation of polar or weakly polar basic or acidic compounds [14].

However, $\mathrm{ZrO}_{2} / \mathrm{SiO}_{2}$ materials cannot be modified in the same manner as silica because of the poor stability of $\mathrm{Zr}-\mathrm{C}$ and $\mathrm{Zr}$ $\mathrm{O}-\mathrm{Si}$ bonds in aqueous solutions [17,19]. Currently, many types of electronegative inorganic and organic phosphates have been modified on the surface of $\mathrm{ZrO}_{2}$ based materials through Lewis acid-base reactions $[17,18,20,21]$. He et al. [20] employed noctadecylphosphonic acid as a derivatization reagent and modified it onto the surface of $\mathrm{MgO}-\mathrm{ZrO}_{2}$ materials, which were then end-capped by trimethylchlorosilane to enhance their chromatographic separation properties. The end-capped SPs exhibited better chromatographic performance towards basic compounds than the SPs without the end-capping reaction. Wang et al. [18] prepared adenosine-bonded $\mathrm{ZrO}_{2} / \mathrm{SiO}_{2}$ microbeads for hydrophilic interac- 


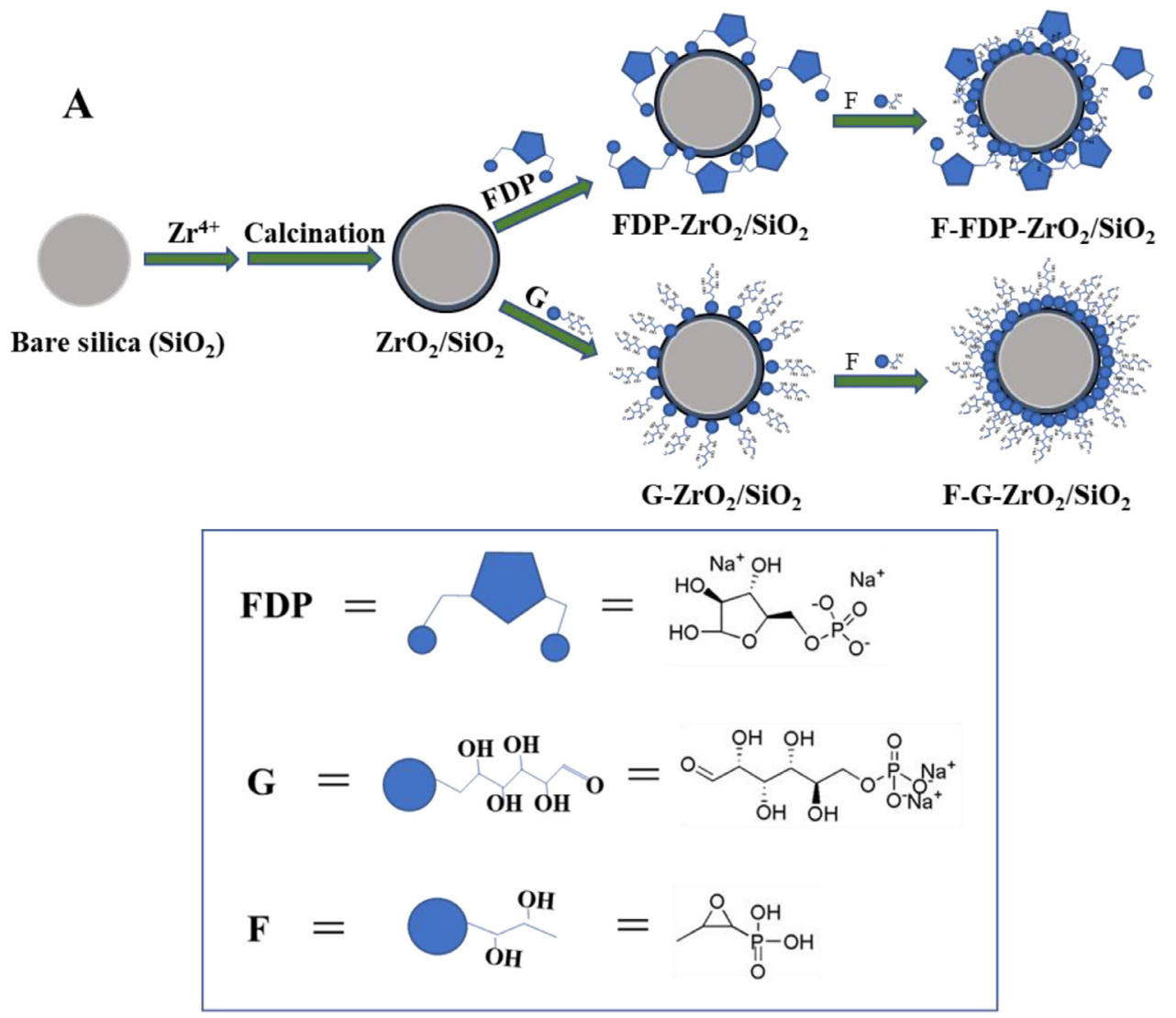

B
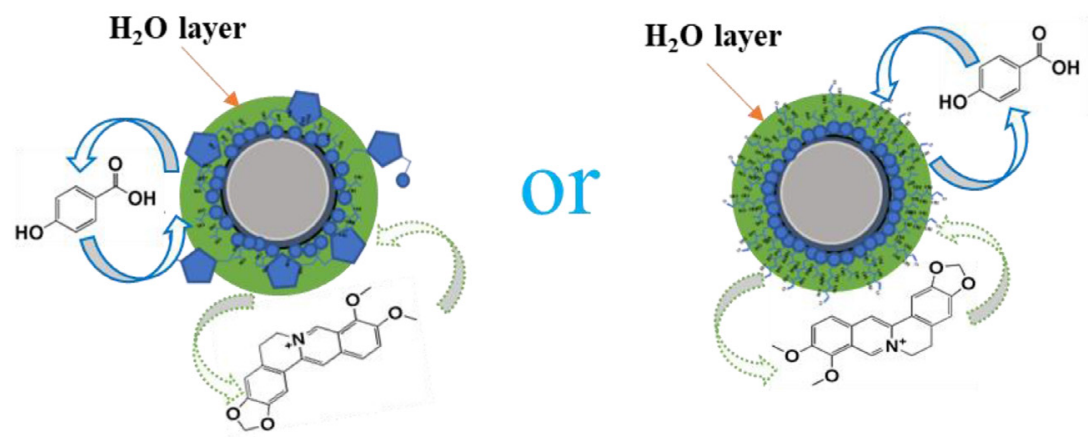

Fig. 1. Synthesis of F end-capped stationary phases (A) and possible principles for the separation of polar analytes (alkaloids and benzoic acids) in HILIC mode (B).

tion liquid chromatography (HILIC) separation of compounds having strong polarity (such as nucleobases, phenolics and alkaloids). However, obvious tailing of chromatographic peaks typically occurs when using chromatographic columns packed with $\mathrm{ZrO}_{2} / \mathrm{SiO}_{2}$ based SPs for the separation of phenols, nucleotide bases, and alkaloids. We speculate that this may be due to the strong interactions between the analytes and the exposed Lewis acid sites, which were caused by the large steric hindrance of the modified phosphate groups. Thus, the development of novel end-capping reagents is vital for overcoming the aforementioned limitations.

Fosfomycin (F) contains a phosphonate group and a glycidyl group (Fig. 1). Hydroxyl groups can be formed in either acidic or basic solutions, owing to the hydrolysis reaction of the glycidyl groups. $\mathrm{F}$ has often been selected as a modification reagent in the preparation of $\mathrm{MgO}-\mathrm{ZrO}_{2}$ based SPs [17]. However, to date, it has not been used as an end-capping reagent. Therefore, in this study, we use $\mathrm{F}$ as an end-capping reagent to prepare novel SPs for the separation of polar compounds in HILIC mode. D-glucose- 6-phosphate disodium salt $(G)$ and D-fructose 1,6-bisphosphate trisodium salt (FDP) modified $\mathrm{ZrO}_{2} / \mathrm{SiO}_{2}$ materials $\left(\mathrm{G}-\mathrm{ZrO}_{2} / \mathrm{SiO}_{2}\right.$ and $\mathrm{FDP}-\mathrm{ZrO}_{2} / \mathrm{SiO}_{2}$ ) were synthesized and then end-capped with $\mathrm{F}$ to improve the chromatographic properties of the SPs for the separation of benzoic acids and alkaloids, respectively. The retention mechanism of the end-capped SPs was evaluated and explained. For comparison, a common small silane agent (trimethylchlorosilane, T) was used to modify $\mathrm{FDP}-\mathrm{ZrO}_{2} / \mathrm{SiO}_{2} \mathrm{SP}$, and the resulting T-FDP- $\mathrm{ZrO}_{2} / \mathrm{SiO}_{2}$ column was employed to separate alkaloids. The results indicated that the obtained novel F end-capped SPs showed satisfactory results for the separation of polar compounds.

\section{Experimental}

\subsection{Chemicals and reagents}

Iressa (98\% purity), F, G and FDP were supplied by Shanghai Yuanye Bio-Technology Co., Ltd (Shanghai, China). End-capping 


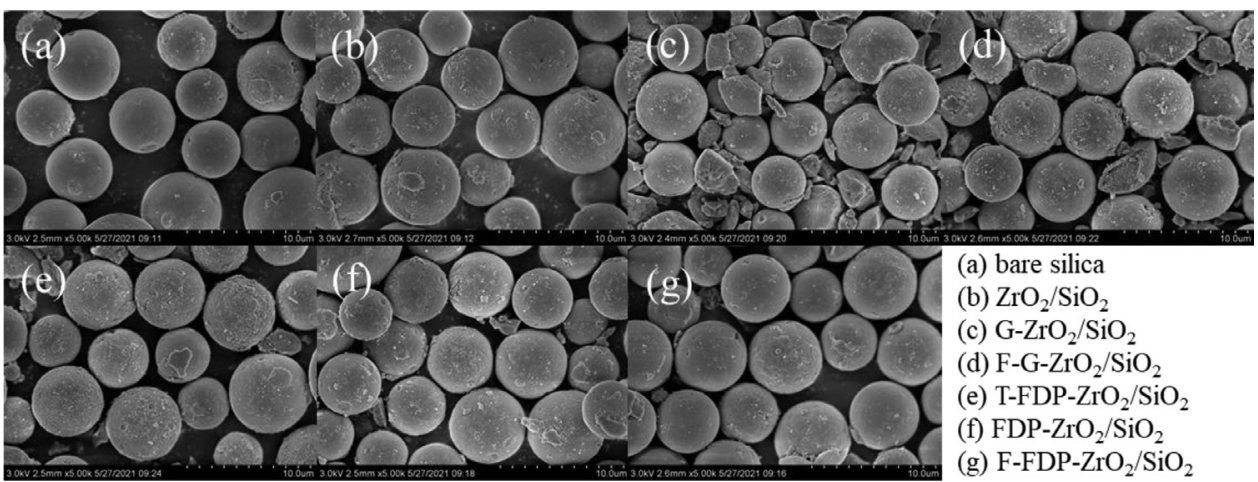

Fig. 2. SEM images of the materials.

reagent $\mathrm{T}$ was supplied by Energy Chemical Co., Ltd. (Shanghai, China). Tetrandrine, lycorine, and tetrahydropalmatine were supplied by Dalian Meilun Biotechnology Co., Ltd. (Dalian, China). Zirconium nitrate pentahydrate, ammonium acetate $\left(\mathrm{NH}_{4} \mathrm{Ac}\right)$, and sodium hydroxide were supplied by Sinopharm Chemical Reagent Co., Ltd. (Shanghai, China). Analytical grade ethanol was purchased from Damao Chemical Reagent Factory (Tianjin, China). Berberine chloride (98\% purity) was purchased from J\&K Scientific Ltd. (Beijing, China). Chromatographic grade methanol $\left(\mathrm{CH}_{3} \mathrm{OH}\right)$ and acetonitrile (ACN) were obtained from Tedia Inc. (Fairfield, USA). Analytical grade hydrochloric acid, nicotinic acid, acetic acid, ammonia solution, p-hydroxybenzoic acid, benzoic acid, and benzene were purchased from Kermel (Tianjin, China). Bare silica microspheres, having a particle size of $5 \mu \mathrm{m}$, surface area of $300 \mathrm{~m}^{2}$ $\mathrm{g}^{-1}$, and pore size of $100 \AA$, were obtained from Fuji Silysia Chemical Ltd. (Kasugai, Japan). Silica based SPs (5 $\mu \mathrm{m}, 100 \AA$ A ) modified with amino and diol groups were supplied by Fuji Silysia Chemical Ltd. (Kasugai, Japan). Deionized purified water, used throughout the study for aqueous solution preparation, was obtained from Hangzhou Wahaha Group Co., Ltd. (Hangzhou, China).

\subsection{Instruments and conditions}

The packed capillary column $(300 \times 0.53 \mathrm{~mm}$ i.d. $)$ evaluation was conducted using an HPLC instrument equipped with quaternary pumps (Agilent 1260, USA), a manual injection valve with an internal loop of $100 \mathrm{~nL}$ (Valco, USA), and a UV detector (an on-column type) from JASCO corporation (Tokyo, Japan). A splitter (tee-piece) was employed to maintain a constant column flow velocity. Finally, the results were obtained and analyzed by using an N2000 chromatographic workstation (Zhejiang University, China).

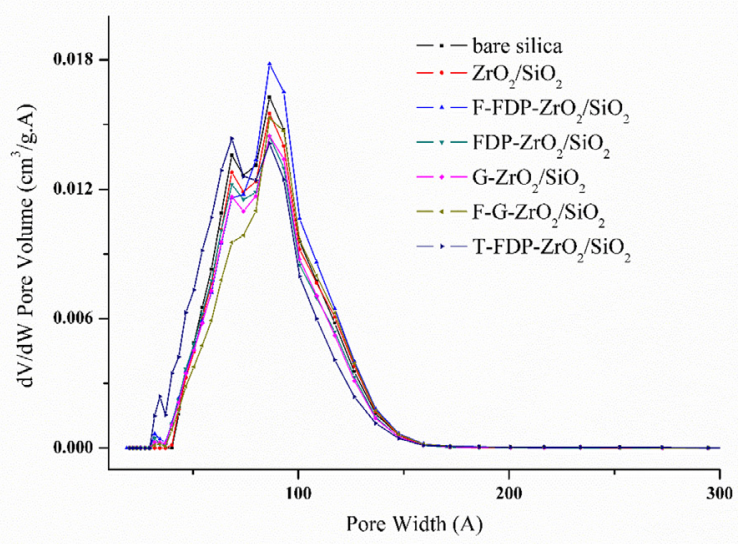

Fig. 3. Pore size distribution based on $\mathrm{N}_{2}$ adsorption data of the materials.
The packed stainless-steel column (150 $\mathrm{mm} \times 2.1 \mathrm{~mm}$ i.d.) was evaluated by using an Agilent 1260 equipped with a diode array detector.

Scanning electron microscopy (SEM, HITACHI S-4800, Japan), along with energy dispersion spectrum (EDS), was utilized to examine the morphology and wt.\% of $\mathrm{Zr}$ on the surface of the materials. Inductively coupled plasma-atomic emission spectrometry (ICP-AES, PerkinElmer, USA) was used to measure the $\mathrm{Zr}$ content in the $\mathrm{ZrO}_{2} / \mathrm{SiO}_{2}$ microbeads. A high-resolution transmission electron microscope (Tecnai G2 F20 S-TWIN, FEI Company, USA) was used to further determine the morphology of the materials. The Fourier transform infrared (FT-IR) spectra of the materials were collected by using FT-IR spectrometer (ThermoFisher Scientific, USA). Thermogravimetric analyzes (TGA) were performed by using an instrument (Mettler 5MP-400W, METTLER-TOLEDO, Switzerland) in the temperature range of $30-900{ }^{\circ} \mathrm{C}$ at a heating rate of $10{ }^{\circ} \mathrm{C} / \mathrm{min}$. Nitrogen adsorption-desorption measurements were performed on a QuadraSorb SI4 (Florida, USA) apparatus, before measurement, and the materials were dried at $60{ }^{\circ} \mathrm{C}$ in vacuum for $6 \mathrm{~h}$. The carbon content of the SPs was determined by using a Vario EL III elemental analysis instrument (Elementar, Hanau, Germany).

\subsection{Preparation and packing of SPS}

\subsubsection{Preparation of $\mathrm{ZrO}_{2} / \mathrm{SiO}_{2}$ material}

Similar to our previous work [22], $\mathrm{ZrO}_{2} / \mathrm{SiO}_{2}$ mesoporous microspheres were prepared as follows. Silica microspheres (5 g) were immersed in an aqueous solution of $0.1 \mathrm{M} \mathrm{NaOH}$ and stirred for half an hour. Then, they were washed with deionized water more than six times, and vacuum-dried under $55^{\circ} \mathrm{C}$. Subsequently, $1 \mathrm{~g}$ of the activated bare silica was rapidly added into a $0.01 \mathrm{M} \mathrm{HCl}$ solution containing $0.5 \mathrm{M}$ zirconium nitrate pentahydrate at $70{ }^{\circ} \mathrm{C}$ and stirred for approximately $2 \mathrm{~h}$. The prepared $\mathrm{ZrO}_{2} / \mathrm{SiO}_{2}$ material was obtained by centrifugation, and then washed separately with both deionized water and ethanol approximately three times each. The obtained material was dried at $60{ }^{\circ} \mathrm{C}$ for approximately $8 \mathrm{~h}$ and calcined at $550{ }^{\circ} \mathrm{C}$ for approximately $6 \mathrm{~h}$ in an air atmosphere in a furnace.

\subsubsection{Preparation of $\mathrm{G}$ modified $\mathrm{ZrO}_{2} / \mathrm{SiO}_{2}\left(\mathrm{G}-\mathrm{ZrO}_{2} / \mathrm{SiO}_{2}\right)$ materials}

The $\mathrm{G}-\mathrm{ZrO}_{2} / \mathrm{SiO}_{2}$ material was prepared by adding $0.4 \mathrm{~g}$ of the $\mathrm{ZrO}_{2} / \mathrm{SiO}_{2}$ material into $20 \mathrm{~mL}$ of an aqueous solution containing $20 \mathrm{mM}$ of $\mathrm{G}$, followed by vigorous stirring at $60{ }^{\circ} \mathrm{C}$ for $15 \mathrm{~h}$. The resulting particles were collected and separately washed thrice with deionized water and ethanol. The resulting $\mathrm{G}-\mathrm{ZrO}_{2} / \mathrm{SiO}_{2}$ material was dried in a vacuum oven at $55{ }^{\circ} \mathrm{C}$ for approximately $8 \mathrm{~h}$ and stored in capped bottles until modification in the next step. The FDP- $\mathrm{ZrO}_{2} / \mathrm{SiO}_{2}$ materials were synthesized using a similar approach. 

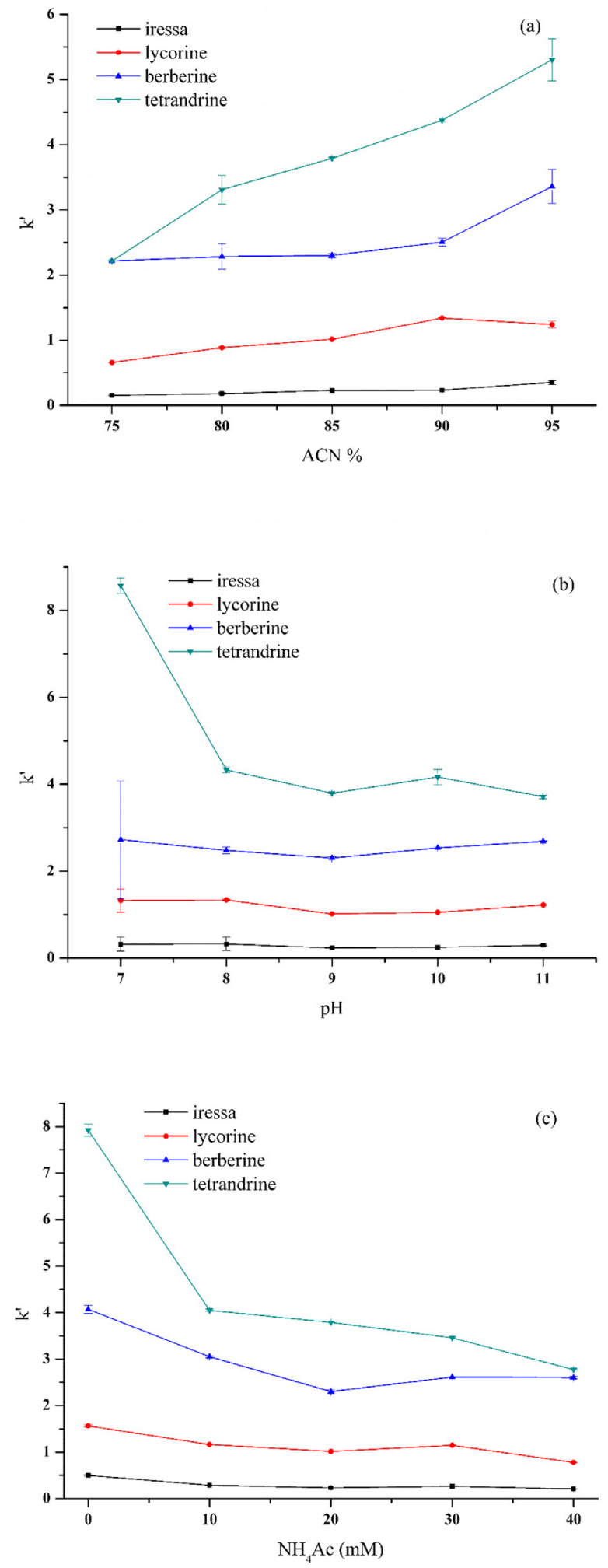

Fig. 4. Effects of $\mathrm{ACN}$ concentration (a), $\mathrm{pH}$ for aqueous solution (b) and NH4Ac content (c) on the retention factors of alkaloids from the F-FDP- $\mathrm{ZrO}_{2} / \mathrm{SiO}_{2}$ column. Chromatographic conditions: (a) $\mathrm{ACN}-20 \mathrm{mM} \mathrm{NH}{ }_{4} \mathrm{Ac}$ ( $\mathrm{pH}=9.0$ ), (b) $85 \% \mathrm{ACN}-15 \%$ $20 \mathrm{mM} \mathrm{NH}_{4} \mathrm{Ac}$, and (c) $85 \% \mathrm{ACN}-15 \% \mathrm{NH}_{4} \mathrm{Ac} / \mathrm{ammonia}(\mathrm{pH}=9.0)$.

\subsubsection{End-capping of $\mathrm{G}-\mathrm{ZrO}_{2} / \mathrm{SiO}_{2}$ or $\mathrm{FDP}-\mathrm{ZrO} \mathrm{SiO}_{2}$ materials with $\mathrm{F}$}

The preparation of $\mathrm{F}-\mathrm{G}-\mathrm{ZrO}_{2} / \mathrm{SiO}_{2}$ SPs was based on the Lewis acid-base effect between $\mathrm{F}$ and $\mathrm{G}-\mathrm{ZrO}_{2} / \mathrm{SiO}_{2}$ porous microspheres. $\mathrm{G}-\mathrm{ZrO}_{2} / \mathrm{SiO}_{2}$ porous microspheres $(0.3 \mathrm{~g})$ were suspended in $20 \mathrm{~mL}$ of an aqueous solution containing $0.3 \mathrm{~g}$ of $\mathrm{F}$, followed by vigorous stirring at $60{ }^{\circ} \mathrm{C}$ for $12 \mathrm{~h}$. The obtained material was washed three times separately with deionized water and ethanol. Finally, the obtained $\mathrm{F}-\mathrm{G}-\mathrm{ZrO}_{2} / \mathrm{SiO}_{2}$ material was dried at $55{ }^{\circ} \mathrm{C}$ for $8 \mathrm{~h}$ and stored in centrifugal tubes. F-FDP- $\mathrm{ZrO}_{2} / \mathrm{SiO}_{2}$ microspheres were synthesized by applying a similar process with minor modifications using $\mathrm{FDP}-\mathrm{ZrO}_{2} / \mathrm{SiO}_{2}$ porous microspheres instead of $\mathrm{F}-\mathrm{G}$ $\mathrm{ZrO}_{2} / \mathrm{SiO}_{2}$ porous microspheres.

\subsubsection{End-capping of $\mathrm{FDP}-\mathrm{ZrO}_{2} / \mathrm{SiO}_{2}$ material with $\mathrm{T}$}

FDP-Z $\mathrm{ZrO}_{2} / \mathrm{SiO}_{2}(1 \mathrm{~g})$ was dissolved in $50 \mathrm{~mL}$ of anhydrous toluene, followed by the addition of end-capping reagent $T$. The dispersion was stirred at a suitable rate for $24 \mathrm{~h}$ under $\mathrm{N}_{2}$ protection. The resulting T-FDP- $\mathrm{ZrO}_{2} / \mathrm{SiO}_{2} \mathrm{SP}$ was collected via centrifugation and washed successively with anhydrous toluene and ethanol. Finally, the $\mathrm{T}-\mathrm{G}-\mathrm{ZrO}_{2} / \mathrm{SiO}_{2}$ material was dried at $55{ }^{\circ} \mathrm{C}$ overnight and stored in centrifugal tubes.

\subsection{Investigation of column properties}

\subsubsection{Column preparation}

The materials were packed into capillary columns by using a dry packing method, as previously mentioned [23]. In the procedure, fused-silica capillary tubing $(300 \mathrm{~mm} \times 0.53 \mathrm{~mm}$ i.d.) supplied by Reafine Chromatography Ltd. (Hebei, China) was used. In the evaluation procedure, a split ratio of 1:100 was chosen. The detection window was prepared by removing the polyimide coating connected to an empty capillary (100 $\mu \mathrm{m}$ i.d.). Acidic and alkaline analytes were utilized to evaluate the performance of the column. The stainless-steel column $(150 \mathrm{~mm} \times 2.1 \mathrm{~mm}$ i.d.) was packed by employing a slurry method under a pressure of $50 \mathrm{MPa}$. The column was then flushed with ACN $(1.0 \mathrm{~mL} / \mathrm{min})$ by using an Agilent 1260 for more than 20 column volumes before evaluation.

\subsubsection{Standard solutions preparation and column evaluation}

The acidic analytes were a mixture of benzoic acid $(1000 \mathrm{mg}$ $\left.\mathrm{L}^{-1}\right)$, p-hydroxybenzoic acid $\left(1000 \mathrm{mg} \mathrm{L}^{-1}\right)$ and nicotinic acid (1000 $\left.\mathrm{mg} \mathrm{L}^{-1}\right)$. These were eluted using a mobile phase of ACN$20 \mathrm{mM} \mathrm{NH}_{4}$ Ac/acetic acid at $\mathrm{pH}=4.0(88: 12, \mathrm{v} / \mathrm{v})$ as the solvent and were detected at $230 \mathrm{~nm}$. The basic analyte mixture was as follows: $900 \mathrm{mg} \mathrm{L}^{-1}$ of berberine, $800 \mathrm{mg} \mathrm{L}^{-1}$ of iressa, $1300 \mathrm{mg}$ $\mathrm{L}^{-1}$ of lycorine, $900 \mathrm{mg} \mathrm{L}^{-1}$ of tetrahydropalmatine, and $2100 \mathrm{mg}$ $\mathrm{L}^{-1}$ of tetrandrine. These were eluted using a mobile phase of $\mathrm{ACN}$ $20 \mathrm{mM} \mathrm{NH}_{4} \mathrm{Ac} / \mathrm{ammonia}$ at $\mathrm{pH}=9.0(85: 15, \mathrm{v} / \mathrm{v})$ and were detected at $280 \mathrm{~nm}$. The retention factor $(k)$ can be obtained based on the following equation: $k=\left(t_{\mathrm{r}}-t_{0}\right) / t_{0}$, where $t_{\mathrm{r}}$ is the retention time of the analyte and $t_{0}$ is the retention time of the unretained compound. The $k$ values represent retention of analyte. The evaluation procedure was performed at about $25^{\circ} \mathrm{C}$.

\subsubsection{Acid-base stability investigation}

In this study, the acid-base stability of the F-FDP- $\mathrm{ZrO}_{2} / \mathrm{SiO}_{2}$ column was evaluated under the highest and lowest $\mathrm{pH}$ conditions for five days. The base stability of the F-FDP- $\mathrm{ZrO}_{2} / \mathrm{SiO}_{2}$ column was studied by using berberine and naphthalene as analytes, and the separation was performed under the following conditions: 85:15 $(\mathrm{v} / \mathrm{v}) \mathrm{ACN}: 20 \mathrm{mM} \mathrm{NH}_{4} \mathrm{Ac}-\mathrm{NaOH}(\mathrm{pH}=12)$. The acid stability of the F-FDP- $\mathrm{ZrO}_{2} / \mathrm{SiO}_{2}$ column was investigated by using benzoic acid and naphthalene as the target analytes, and a mobile phase of 85:15 (v/v) ACN:20 mM NH 4 Ac- $\mathrm{CH}_{3} \mathrm{COOH}(\mathrm{pH}=3.0)$ was utilized in the process. The relative retention factors were also examined.

\subsubsection{Analysis of benzoic acid in Sprite}

At present, benzoic acid is universally used as an antiseptic and is added to many prepared foods and drinks. Thus, the analysis of this antiseptic is important. Standard solutions of benzoic acid 

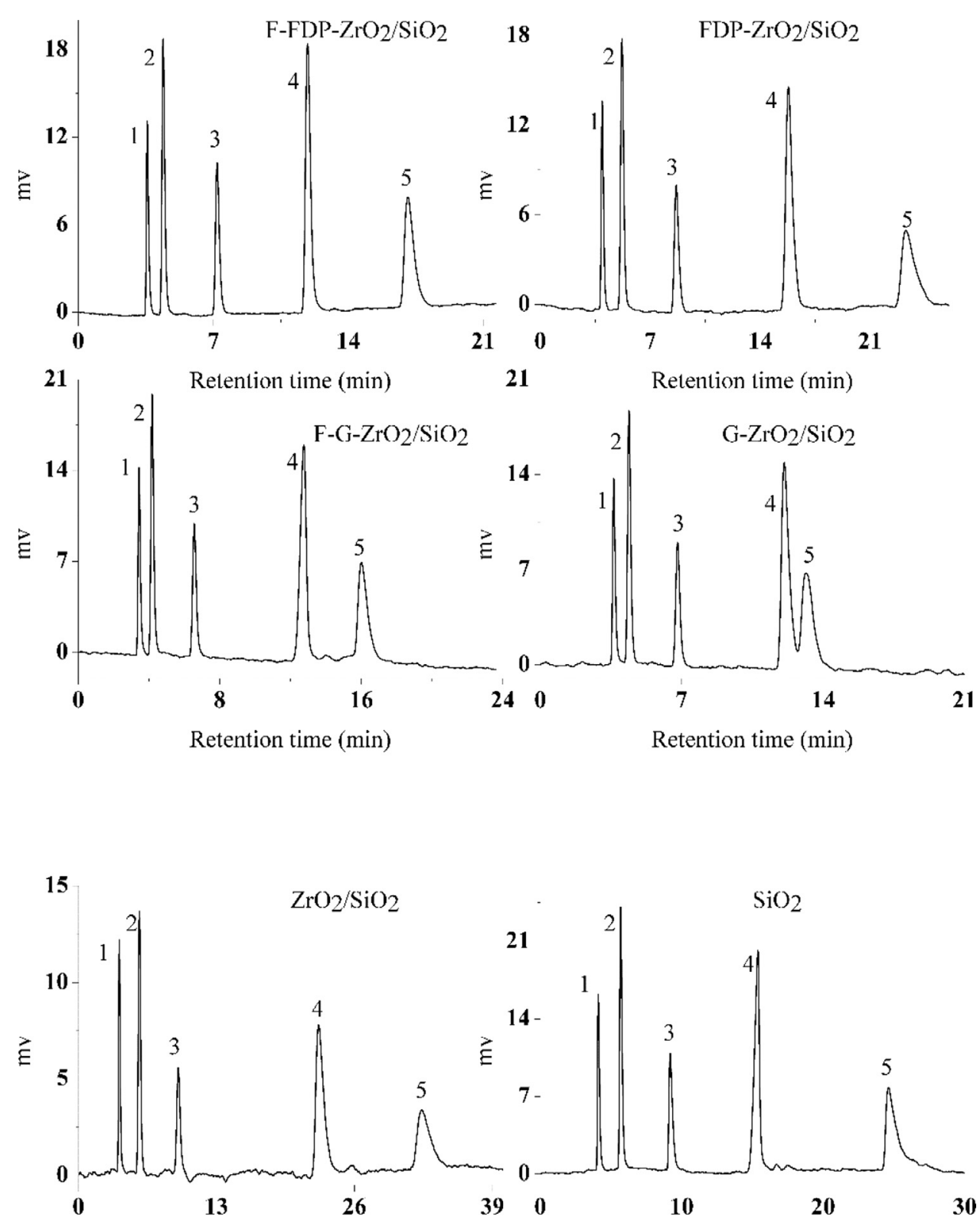

Retention time (min)

60

Retention time (min)
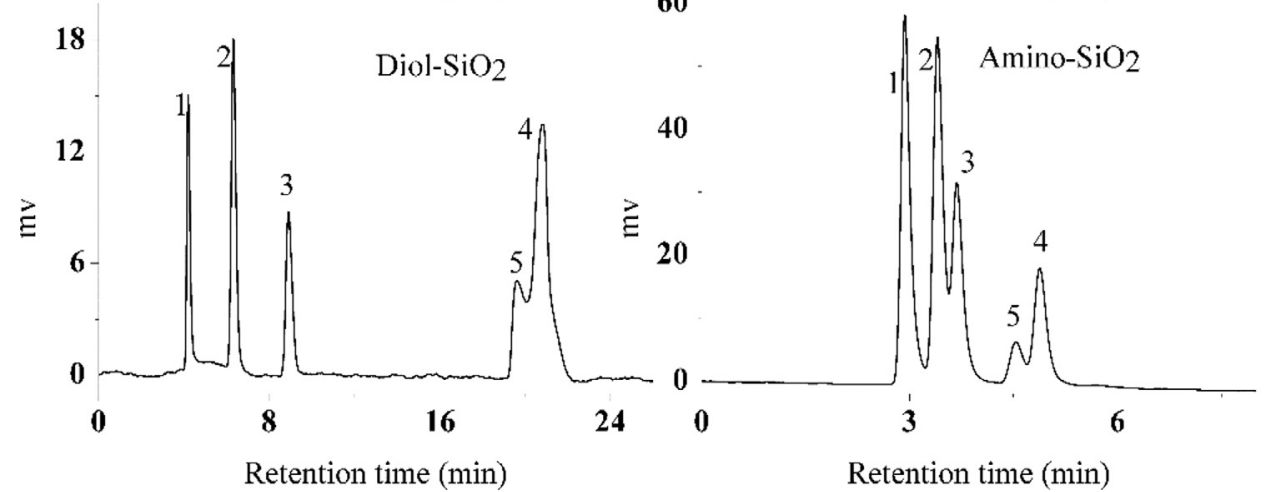

Fig. 5. Chromatographic peaks of alkaloids: (1) tetrahydropalmatine, (2) iressa, (3) lycorine, (4) berberine, (5) tetrandrine. Column: capillary column (300 mm $\times 0.53 \mathrm{~mm}$ i.d.). Chromatographic conditions: $85 \% \mathrm{ACN}-15 \% 20 \mathrm{mM} \mathrm{NH} 4 \mathrm{Ac} /$ ammonia with $\mathrm{pH}$ of 9.0 with detection by UV at $280 \mathrm{~nm}$. 

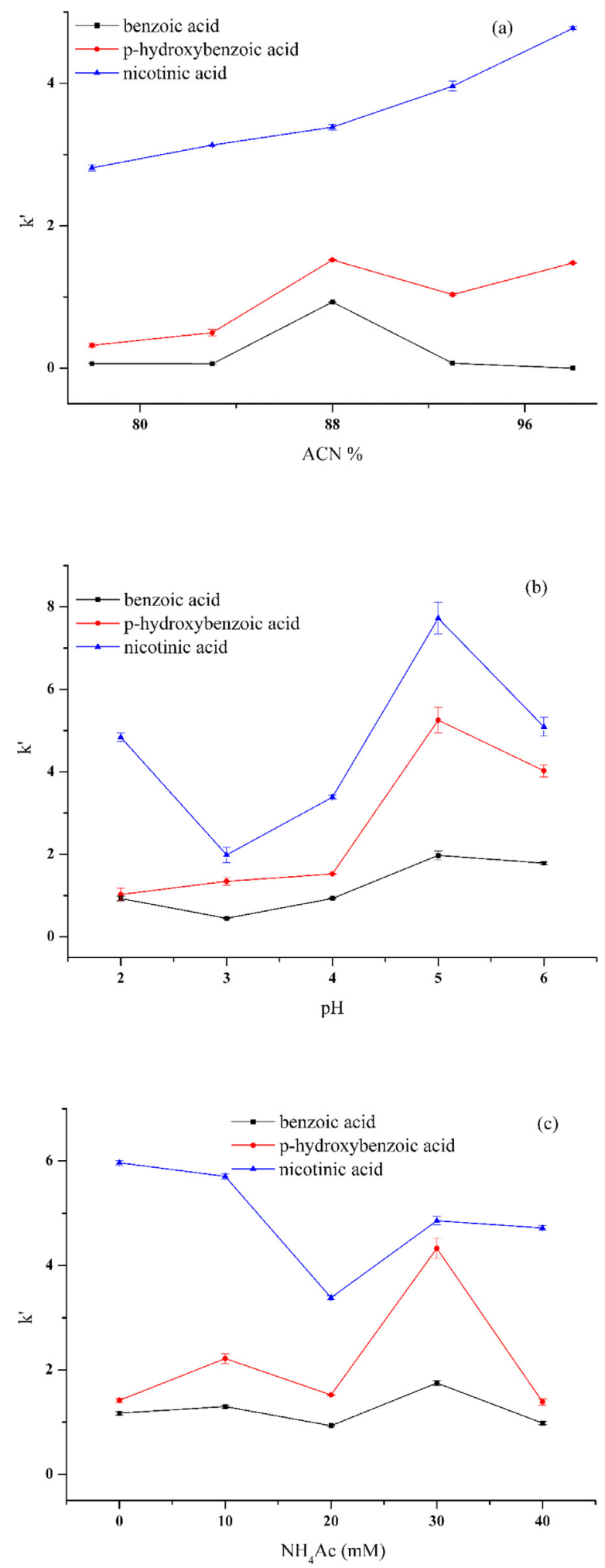

Fig. 6. Effects of $\mathrm{ACN}$ concentration (a), $\mathrm{pH}$ for aqueous solution (b), and $\mathrm{NH}_{4} \mathrm{Ac}$ concentration (c) on the $\mathrm{k}$ of the benzoic acids on the F-FDP- $\mathrm{ZrO}_{2} / \mathrm{SiO}_{2}$ column. Chromatographic conditions: (a) ACN-20 mM NH${ }_{4} \mathrm{Ac}(\mathrm{pH}=4.0$ ), (b) $88 \% \mathrm{ACN}-12 \%$ $20 \mathrm{mM} \mathrm{NH}_{4} \mathrm{Ac}$, and (c) $88 \% \mathrm{ACN}-12 \% \mathrm{NH}_{4} \mathrm{Ac} / \mathrm{ammonia}(\mathrm{pH}=4.0)$. were prepared $\left(10,50,100,500\right.$, and $\left.1000 \mathrm{mg} \mathrm{L}^{-1}\right)$, and a calibration curve was drawn. Sprite $(20 \mathrm{~mL})$ was added into a $25 \mathrm{~mL}$ plastic centrifuge tube and degassed with an ultrasonic cleaner for approximately $15 \mathrm{~min}$. Next, ammonium hydroxide (25\%) was added into the solution to neutralize the $\mathrm{pH}$. After that, water was added into the centrifuge tube to $25 \mathrm{~mL}$, and the solution was filtered through a filter membrane with a pore size of $0.22 \mu \mathrm{m}$.

\section{Results and discussion}

\subsection{Synthesis of $\mathrm{F}$ end-capped $\mathrm{ZrO}_{2} / \mathrm{SiO}_{2}$ materials}

The synthesis of $\mathrm{ZrO}_{2} / \mathrm{SiO}_{2}$ based SPs is schematically shown in Fig. $1 \mathrm{~A}$. Firstly, $\mathrm{ZrO}_{2} / \mathrm{SiO}_{2}$ was prepared by adding bare silica porous microspheres to an aqueous solution containing $\mathrm{Zr}^{4+}$. The subsequent hydrolysis reaction of $\mathrm{Zr}^{4+}$ and the calcination procedure resulted in the formation of a $\mathrm{ZrO}_{2}$ shell on the silica microbeads. Lewis base reagents $\mathrm{G}$ or FDP were adsorbed onto the Lewis acid sites on the inner and outer surfaces of the $\mathrm{ZrO}_{2} / \mathrm{SiO}_{2}$ microbeads. Finally, the residual Lewis acid sites of the synthesized materials ( $\mathrm{FDP}-\mathrm{ZrO}_{2} / \mathrm{SiO}_{2}$ or $\mathrm{G}-\mathrm{ZrO}_{2} / \mathrm{SiO}_{2}$ ) were end-capped with the small molecule, $\mathrm{F}$, as shown in Fig. $1 \mathrm{~A}$.

\subsection{Characterization of the materials}

The results of the ICP-AES measurement indicated that the wt.\% of $\mathrm{Zr}$ on the surface of the $\mathrm{ZrO}_{2} / \mathrm{SiO}_{2}$ particles was $5.05 \%$, and no $\mathrm{Zr}$ was detected on bare silica, confirming that the $\mathrm{ZrO}_{2} / \mathrm{SiO}_{2}$ materials were successfully synthesized. As shown in the SEM images (Fig. 2), the prepared particles $\left(\mathrm{ZrO}_{2} / \mathrm{SiO}_{2}, \mathrm{G}-\mathrm{ZrO}_{2} / \mathrm{SiO}{ }_{2}, \mathrm{~F}-\mathrm{G}-\right.$ $\mathrm{ZrO}_{2} / \mathrm{SiO}_{2}$, T-FDP-ZrO $/ \mathrm{SiO}_{2}, \mathrm{FDP}-\mathrm{ZrO}_{2} / \mathrm{SiO}_{2}$, and F-FDP-ZrO $\left.2 / \mathrm{SiO}_{2}\right)$ have particle sizes of approximately $5 \mu \mathrm{m}$ and are spherical with no agglomerated appearance, which are very similar to the appearance of the bare silica particles. This illustrates that the precipitation of the $\mathrm{ZrO}_{2}$ layer on the surface of the silica sphere did not cause any aggregation, conglomeration, or cracks. The well preserved morphology of metal oxide coated silica is of great significance for the final chromatographic separation. The EDS data further verified the successful coating of the $\mathrm{ZrO}_{2}$ layer on the surface of the silica microbeads (Table 1). As observed in the TEM images (Fig. S1), homogeneous and rough layers of materials are modified on the surface of the silica particles.

In the FT-IR spectra (Fig. S2), the peaks at 464,800, and $1085 \mathrm{~cm}^{-1}$ correspond to the bending of the $\mathrm{Si}-\mathrm{O}-\mathrm{Si}$ group. In the $\mathrm{ZrO}_{2} / \mathrm{SiO}_{2}$ based materials, the stretching of $\mathrm{Si}-\mathrm{OH}$ near $973 \mathrm{~cm}^{-1}$ disappeared owing to the successful coating of the $\mathrm{ZrO}_{2}$ layer. In the F-FDP- $\mathrm{ZrO}_{2} / \mathrm{SiO}_{2}$ and $\mathrm{F}-\mathrm{G}-\mathrm{ZrO}_{2} / \mathrm{SiO}_{2}$ materials, the C-H stretching vibration absorption near $2985 \mathrm{~cm}^{-1}$ demonstrated the successful modification of the organic groups. As shown in Fig. S3, the weight of the materials decreased when heated from $30^{\circ} \mathrm{C}$ to $260{ }^{\circ} \mathrm{C}$, indicating the evaporation of surface water and removal of unstable compounds. The weight loss of the materials modified by the organic groups was greater than that of the bare silica and $\mathrm{ZrO}_{2} / \mathrm{SiO}_{2}$ particles. These results further confirmed the successful modification of the organic groups. The TGA curves of the materials were nearly a plateau in the range of $260-460{ }^{\circ} \mathrm{C}$. After $460{ }^{\circ} \mathrm{C}$, a minor weight loss of the materials occurred (approximately $1 \%$ ).

Multipoint nitrogen adsorption-desorption experiments were used to measure the pore structure of the materials. The pore size distribution of the materials is shown in Fig. 3, and the pore structure data are listed in Table 2. Most materials display a narrow pore size distribution (approximately $9 \mathrm{~nm}$ ). The $\mathrm{N}_{2}$ adsorptiondesorption isotherms depicted in Fig. S4 indicate that the materials exhibit type IV isotherms, suggesting that the pore structure of the materials is almost cylindrical, the results show that the mesopores of the prepared materials are still well-preserved after modification 

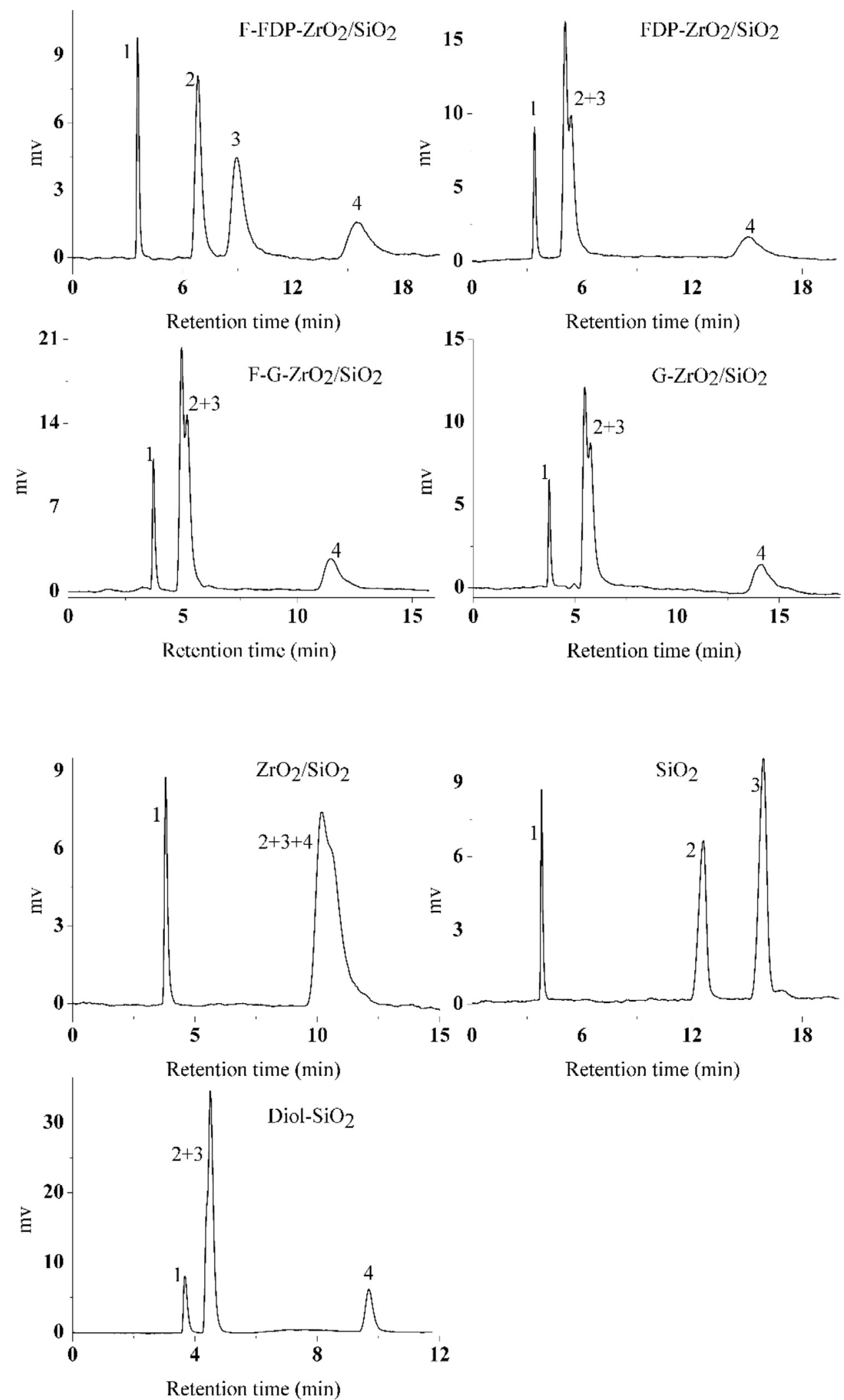

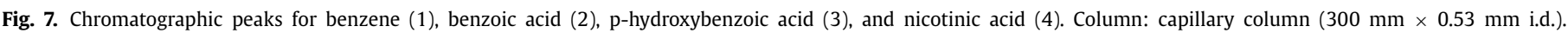
Chromatographic conditions: $88 \% \mathrm{ACN}-12 \% 20 \mathrm{mM} \mathrm{NH}$ Ac/acetic acid solution with $\mathrm{pH}$ of 4.0 with detection by UV at $230 \mathrm{~nm}$.

Table 1

wt.\% of $\mathrm{Zr}$ on the materials obtained by performing EDS measurement.

\begin{tabular}{|c|c|c|c|c|c|c|c|}
\hline materials & bare silica & $\mathrm{ZrO}_{2} / \mathrm{SiO}_{2}$ & F-FDP-ZrO ${ }_{2} / \mathrm{SiO}_{2}$ & $\mathrm{FDP}-\mathrm{ZrO}_{2} / \mathrm{SiO}_{2}$ & $\mathrm{G}-\mathrm{ZrO}_{2} / \mathrm{SiO}_{2}$ & $\mathrm{~F}-\mathrm{G}-\mathrm{ZrO}_{2} / \mathrm{SiO}_{2}$ & T-FDP-ZrO ${ }_{2} / \mathrm{SiO}_{2}$ \\
\hline wt $\% \mathrm{Zr}$ & $0 \%$ & $2.66 \%$ & $2.72 \%$ & $2.67 \%$ & $2.58 \%$ & $2.53 \%$ & $2.22 \%$ \\
\hline
\end{tabular}


Table 2

Pore structure of the particles.

\begin{tabular}{|c|c|c|c|}
\hline particles & $\mathrm{S}_{\mathrm{BET}}{ }^{\mathrm{a}}\left(\mathrm{m}^{2} \mathrm{~g}^{-1}\right)$ & Mesopore width ${ }^{\mathrm{b}}(\mathrm{nm})$ & Pore volume ${ }^{\mathrm{c}}\left(\mathrm{cm}^{3} \mathrm{~g}^{-1}\right)$ \\
\hline bare silica & 349.56 & 8.96 & 0.91 \\
\hline $\mathrm{ZrO}_{2} / \mathrm{SiO}_{2}$ & 345.89 & 9.06 & 0.88 \\
\hline F-FDP-ZrO ${ }_{2} / \mathrm{SiO}_{2}$ & 365.95 & 9.26 & 0.97 \\
\hline $\mathrm{FDP}-\mathrm{ZrO}_{2} / \mathrm{SiO}_{2}$ & 334.56 & 8.87 & 0.85 \\
\hline $\mathrm{G}-\mathrm{ZrO}_{2} / \mathrm{SiO}_{2}$ & 328.08 & 8.98 & 0.84 \\
\hline $\mathrm{F}-\mathrm{G}-\mathrm{ZrO}_{2} / \mathrm{SiO}_{2}$ & 314.87 & 8.98 & 0.84 \\
\hline T-FDP-ZrO ${ }_{2} / \mathrm{SiO}_{2}$ & 357.31 & 7.71 & 0.88 \\
\hline
\end{tabular}

${ }^{\text {a BET surface area. }}$

${ }^{b} \mathrm{BJH}$ Adsorption average pore width.

cBJH Adsorption cumulative volume of pores between 8.500 and $1500.000 \AA$ radius.

[24]. The excellent physical properties of the prepared particles are very important for HPLC separation.

To further demonstrate the stability and the alkali resistance of the prepared $\mathrm{ZrO}_{2} / \mathrm{SiO}_{2}$ particles, the materials were immersed in a solution containing $\mathrm{NaOH}(0.5 \mathrm{M})$ for $3 \mathrm{~h}$. The morphology of the $\mathrm{ZrO}_{2} / \mathrm{SiO}_{2}$ material changed slightly, while the bare silica was nearly completely dissolved (Fig. S5). These results confirmed that the silica material was successfully covered with a $\mathrm{ZrO}_{2}$ shell, which improved the basic stability of the material. The carbon content of the F-G-ZrO $\mathrm{ZrO}_{2} / \mathrm{SiO}_{2}, \mathrm{G}-\mathrm{ZrO}_{2} / \mathrm{SiO}{ }_{2}, \mathrm{~F}-\mathrm{FDP}-\mathrm{ZrO}_{2} / \mathrm{SiO}_{2}$, FDP$\mathrm{ZrO}_{2} / \mathrm{SiO}_{2}, \mathrm{ZrO}_{2} / \mathrm{SiO}_{2}$, and bare silica materials was determined by elemental analysis. Table S1 indicates that $\mathrm{G}$ and FDP are successfully modified onto the $\mathrm{ZrO}_{2} / \mathrm{SiO}_{2}$ particles. Furthermore, the $\mathrm{G}-\mathrm{ZrO} \mathrm{rO}_{2} / \mathrm{SiO}_{2}$ and $\mathrm{FDP}-\mathrm{ZrO}_{2} / \mathrm{SiO}_{2}$ materials are successfully endcapped by $\mathrm{F}$.

\subsection{Evaluation of $F$ end-capped SPS}

The ideal SP should give high selectivity, good symmetrical peak shape, good chemical stability and incompressibility, low mass transfer resistance and reusability. Alkaloids and benzoic acids (Fig. S6) were chosen as standard polar compounds to evaluate the prepared SPs. The chromatographic properties of the prepared SPs were compared with those of commercial SPs (amino-modified silica and diol-modified silica microbeads).

\subsubsection{Chromatographic separation of alkaloids}

Alkaloids, including tetrahydropalmatine, iressa, lycorine, berberine and tetrandrine, belong to an important family of pharmacologically active compounds that contain an amine nitrogen atom and are usually isolated from herbal medicines [25,26]. However, they are very difficult to retain in reversed-phase liquid chromatography (RPLC) mode [20], leading to the development of $\mathrm{ZrO}_{2}$ based materials to solve the retention problem [18,27,28]. Based on these discoveries, we applied the resulting end-capped $\mathrm{ZrO}_{2} / \mathrm{SiO}_{2} \mathrm{SPs}$ to separate a mixture of alkaloids.

As shown in Fig. 4, the performance of the chromatographic column packed with F-FDP-Z $\mathrm{ZrO}_{2} / \mathrm{SiO}_{2}$ SPs for the alkaloids exhibits a characteristic HILIC retention mode: the retention time of the polar analytes increases when the content of $\mathrm{ACN}$ increases from 75 to $95 \%$. The increase in the $\mathrm{NH}_{4} \mathrm{Ac}$ content (from $0 \mathrm{mM}$ to $40 \mathrm{mM}$ ) and $\mathrm{pH}$ (from 7 to 11) of the mobile phase resulted in a decrease in k'. This was mainly due to the interactions of electrostatic repulsion, ion exchange and hydrogen bonding between the SPs and the analytes. The chromatographic properties of the commercial diol-modified silica SPs column were evaluated using alkaloids under different mobile phases (Fig. S7). The optimal mobile phase was determined to be ACN-20 mM NH 4 Ac/ammonia solution at $\mathrm{pH}=9.0(85: 15, \mathrm{v} / \mathrm{v})$.

Fig. 5 and Table 3 present the chromatographic separation performances of columns packed with the prepared F-FDP-Z $\mathrm{ZrO}_{2} / \mathrm{SiO}_{2}$, F-G-ZrO $\mathrm{Zr}_{2} / \mathrm{SiO}_{2}, \mathrm{FDP}-\mathrm{ZrO}_{2} / \mathrm{SiO}_{2}, \mathrm{G}-\mathrm{ZrO}_{2} / \mathrm{SiO}_{2}, \mathrm{ZrO}_{2} / \mathrm{SiO}_{2}$, and com-

Table 3

Chromatographic data for separation of alkaloids on the stationary phases. Mobile phase: $85 \% \mathrm{ACN}-15 \% 20 \mathrm{mM} \mathrm{NH}_{4} \mathrm{Ac}$ solution at pH 9 . Detection: UV at $280 \mathrm{~nm}$.

\begin{tabular}{|c|c|c|c|c|c|c|c|c|c|}
\hline \multirow[t]{2}{*}{ Compound } & \multicolumn{3}{|c|}{ F-FDP-ZrO ${ }_{2} / \mathrm{SiO}_{2}$} & \multicolumn{3}{|c|}{$\mathrm{FDP}-\mathrm{ZrO}_{2} / \mathrm{SiO}_{2}$} & \multicolumn{3}{|c|}{ F-G-ZrO $/ 2 / \mathrm{SiO}_{2}$} \\
\hline & $\mathrm{N} / \mathrm{m}$ & As & Rs & $\mathrm{N} / \mathrm{m}$ & As & Rs & $\mathrm{N} / \mathrm{m}$ & As & Rs \\
\hline & 15,900 & 1.84 & 2.92 & 11,200 & 1.61 & 3.33 & 11,400 & 1.63 & 2.39 \\
\hline tetrahydropalmatine & & & 7.52 & & & 6.47 & & & 5.91 \\
\hline iressa & 14,200 & 1.68 & 9.34 & 10,500 & 1.48 & 9.20 & 10,900 & 1.48 & 10.03 \\
\hline lycorine & 20,700 & 1.56 & 6.41 & 13,900 & 1.64 & 5.25 & 14,600 & 1.45 & 3.37 \\
\hline berberine & 31,700 & 1.63 & & 21,700 & 1.78 & & 20,300 & 0.74 & \\
\hline tetrandrine & 19,500 & 2.34 & & 10,800 & 2.69 & & 13,900 & 2.11 & \\
\hline \multirow[t]{3}{*}{ Compound } & \multicolumn{3}{|c|}{$\mathrm{G}^{-\mathrm{ZrO}_{2}} / \mathrm{SiO}_{2}$} & \multicolumn{3}{|c|}{$\mathrm{ZrO}_{2} / \mathrm{SiO}_{2}$} & \multicolumn{3}{|c|}{ Bare Silica } \\
\hline & $\mathrm{N} / \mathrm{m}$ & As & Rs & $\mathrm{N} / \mathrm{m}$ & As & Rs & $\mathrm{N} / \mathrm{m}$ & As & Rs \\
\hline & 12,400 & 1.72 & 2.41 & 10,500 & 1.49 & 4.67 & 12,800 & 2.09 & 4.66 \\
\hline tetrahydropalmatine & & & 5.92 & & & 6.04 & & & 7.58 \\
\hline iressa & 11,600 & 1.44 & 8.21 & 10,400 & 1.31 & 11.08 & 17,100 & 1.77 & 9.44 \\
\hline lycorine & 15,900 & 1.47 & 1.06 & 12,200 & 1.64 & 4.39 & 20,600 & 2.26 & 8.03 \\
\hline berberine & 16,000 & 2.34 & & 13,800 & 2.47 & & 30,000 & 0.52 & \\
\hline tetrandrine & 8,100 & 2.08 & & 10,000 & 1.99 & & 19,000 & 4.41 & \\
\hline \multirow[t]{3}{*}{ Compound } & \multicolumn{3}{|c|}{ Diol-modified silica } & \multicolumn{3}{|c|}{ Amino-modified silica } & \multirow{3}{*}{\multicolumn{3}{|c|}{$\begin{array}{l}\text { As: Asymmetry factor } \\
\mathrm{N} / \mathrm{m} \text { : Theoretical plate number } \\
\text { Rs: USP resolution }\end{array}$}} \\
\hline & $\mathrm{N} / \mathrm{m}$ & As & Rs & $\mathrm{N} / \mathrm{m}$ & As & Rs & & & \\
\hline & 12,600 & 1.61 & 5.10 & 7900 & 1.77 & 1.57 & & & \\
\hline tetrahydropalmatine & & & 4.43 & & & 0.79 & & & \\
\hline iressa & 12,000 & 1.35 & 10.30 & 8,200 & 1.27 & 1.97 & & & \\
\hline lycorine & 13,300 & 1.64 & 0.86 & 7,100 & 1.94 & 0.77 & & & \\
\hline berberine & 14,200 & 1.29 & & 6,400 & 0.91 & & & & \\
\hline tetrandrine & 16,900 & 1.26 & & 11,000 & 1.30 & & & & \\
\hline
\end{tabular}


Table 4

Chromatographic data for separation of benzoic acids on the stationary phases. Mobile phase: $88 \% \mathrm{ACN}-12 \% 20 \mathrm{mM} \mathrm{NH}_{4} \mathrm{Ac}$ solution at pH 4 . Detection: UV at $230 \mathrm{~nm}$.

\begin{tabular}{|c|c|c|c|c|c|c|c|c|c|}
\hline \multirow[t]{2}{*}{ Compound } & \multicolumn{3}{|c|}{$\mathrm{F}-\mathrm{FDP}-\mathrm{ZrO}_{2} / \mathrm{SiO}_{2}$} & \multicolumn{3}{|c|}{$\mathrm{FDP} \mathrm{ZrO}_{2} / \mathrm{SiO}_{2}$} & \multicolumn{3}{|c|}{$\mathrm{F}-\mathrm{G}-\mathrm{ZrO}_{2} / \mathrm{SiO}_{2}$} \\
\hline & $\mathrm{N} / \mathrm{m}$ & As & Rs & $\mathrm{N} / \mathrm{m}$ & As & Rs & $\mathrm{N} / \mathrm{m}$ & As & Rs \\
\hline benzene & 12,100 & 1.95 & 6.45 & 12,000 & 1.88 & 3.64 & 18,200 & 1.96 & 3.35 \\
\hline benzoic acid & 6,200 & 1.79 & 1.94 & 4,500 & 1.03 & 0.53 & 7,200 & 0.96 & 0.48 \\
\hline $\begin{array}{l}\text { p-hydroxybenzoic } \\
\text { acid }\end{array}$ & 2,800 & 2.27 & 3.31 & 5,800 & 4.65 & 6.20 & 9,100 & 4.34 & 6.55 \\
\hline nicotinic acid & 2,800 & 2.06 & & 2,700 & 1.75 & & 4,600 & 2.40 & \\
\hline \multirow[t]{2}{*}{ Compound } & \multicolumn{3}{|c|}{$\mathrm{G}-\mathrm{ZrO}_{2} / \mathrm{SiO}_{2}$} & \multicolumn{3}{|c|}{$\mathrm{ZrO}_{2} / \mathrm{SiO}_{2}$} & \multicolumn{3}{|c|}{ Bare Silica } \\
\hline & $\mathrm{N} / \mathrm{m}$ & As & Rs & $\mathrm{N} / \mathrm{m}$ & As & Rs & $\mathrm{N} / \mathrm{m}$ & As & Rs \\
\hline benzene & 18,800 & 1.90 & 4.49 & 15,100 & 1.914 & 5.752 & 12,700 & 2.347 & 2.2 \\
\hline benzoic acid & 7,400 & 0.97 & 0.52 & 2,000 & 3.113 & & 6,800 & 1.083 & 10.18 \\
\hline $\begin{array}{l}\text { p-hydroxybenzoic } \\
\text { acid }\end{array}$ & 8,200 & 4.11 & 7.61 & - & - & & - & - & \\
\hline nicotinic acid & 5,400 & 1.30 & & - & - & & 22900 & 1.415 & \\
\hline \multirow[t]{2}{*}{ Compound } & \multicolumn{3}{|c|}{ Diol-modified silica } & \multicolumn{6}{|c|}{ As: Asymmetry factor } \\
\hline & $\mathrm{N} / \mathrm{m}$ & As & Rs & \multicolumn{6}{|c|}{$\mathrm{N} / \mathrm{m}$ : Theoretical plate number } \\
\hline benzene & 18,900 & 1.89 & 15.23 & \multicolumn{6}{|c|}{ Rs: USP resolution } \\
\hline benzoic acid & 13,900 & 0.73 & 3.60 & & & & & & \\
\hline $\begin{array}{l}\text { p-hydroxybenzoic } \\
\text { acid }\end{array}$ & 22,400 & 0.78 & - & & & & & & \\
\hline nicotinic acid & - & - & & & & & & & \\
\hline
\end{tabular}

mercial SPs (bare silica, amino-modified silica, and diol-modified silica SPs). A baseline separation of alkaloids was achieved with the F-FDP- $\mathrm{ZrO}_{2} / \mathrm{SiO}_{2}$ column, yielding the overall best column efficiency of 31,700 plates/m for berberine. The chromatographic performance of the $\mathrm{F}-\mathrm{G}-\mathrm{ZrO}_{2} / \mathrm{SiO}_{2} \mathrm{SP}$ was better than that of the G$\mathrm{ZrO}_{2} / \mathrm{SiO}_{2} \mathrm{SP}$. The results indicate that the end-capping process is of great significance for improving chromatographic performance. To further investigate the advantages of the end-capping reagent $F$, trimethylchlorosilane (a common small silane) was used as an endcapping reagent on the surface of $\mathrm{FDP}-\mathrm{ZrO} \mathrm{rO}_{2} / \mathrm{SiO}_{2}$. The resulting SP (T-FDP-ZrO $\mathrm{Zr}_{2} / \mathrm{SiO}_{2}$ ) was slurry-packed into a stainless-steel column $\left(150 \mathrm{~mm} \times 2.1 \mathrm{~mm}\right.$ i.d.). The T-FDP- $\mathrm{ZrO}_{2} / \mathrm{SiO}_{2}$ column was used for the separation of alkaloids; however, berberine and tetrandrine could not be separated, as shown in Fig. S8. F showed superior end-capping properties over T. Finally, the separation reproducibility of the F-FDP-Z $\mathrm{ZrO}_{2} / \mathrm{SiO}_{2}$ SP for alkaloids was evaluated. The relative standard deviation (RSD) values for batch-to-batch and runto-run were less than $4.9 \%$ and $0.9 \%$, respectively, suggesting that F-FDP- $\mathrm{ZrO}_{2} / \mathrm{SiO}_{2}$ has good reproducibility (Fig. S9).

\subsubsection{Separation of benzoic acids}

Benzoic acids have garnered considerable interest in the fields of food and drug production [29]; however, it has been reported that benzoic acids cannot be separated on a bare $\mathrm{ZrO}_{2}$ column. A possible reason for this is that the benzoic acids could be strongly adsorbed by the Lewis acid sites on the $\mathrm{ZrO}_{2}$ materials [30]. A mixture of benzene, benzoic acid, nicotinic acid, and p-hydroxy benzoic acid was utilized to explore the retention mechanism of the columns packed with synthesized SPs and commercial SPs (including bare silica and diol-modified silica). As shown in Fig. 6, on the F-FDP- $\mathrm{ZrO}_{2} / \mathrm{SiO}_{2}$ column, the elution orders of benzoic acids were benzene $<$ benzoic acid $<$ p-hydroxy benzoic acid $<$ nicotinic acid, which are consistent with their log $\mathrm{P}$ values (the partition coefficients of the compounds between octanol and water, as shown in Fig. S6). The k' value of most analytes increases with an increase in the ACN content in the mobile phase. The $\mathrm{NH}_{4} \mathrm{Ac}$ content in the mobile phase and the $\mathrm{pH}$ influence on the $\mathrm{k}$ ' value of the benzoic acids. These results imply that the separation of benzoic acids occurs via mixed-mode retention mechanisms, including hydrophilic interactions, ion exchange, and hydrogen bond interactions.

As shown in Fig. 7 and Table 4, the chromatographic properties of the prepared F-FDP- $\mathrm{ZrO}_{2} / \mathrm{SiO}_{2}$ column are better than those of the commercial columns. These results suggest that $\mathrm{F}$ can be used as an end-capping reagent. The batch-to-batch and run-to-run reproducibility of the F-FDP- $\mathrm{ZrO}_{2} / \mathrm{SiO}_{2}$ column for the separation of benzoic acids was also evaluated. Three batches of F-FDP- $\mathrm{ZrO}_{2} / \mathrm{SiO}_{2}$ materials were synthesized under the same reaction conditions, and dry-packed into columns. As shown in Fig. S10, the batch-tobatch and run-to-run RSD values are less than $6.2 \%$ and $1 \%$, respectively. The results indicated that the end-capped SPs have good re-
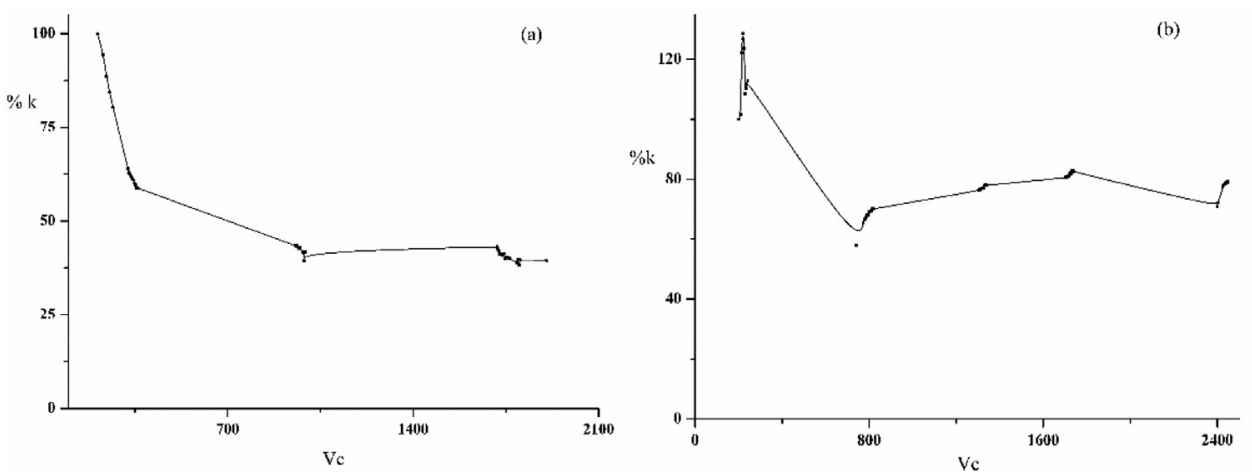

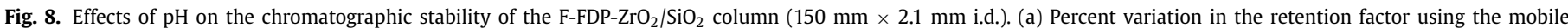

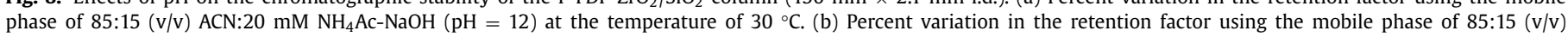
$\mathrm{ACN}: 20 \mathrm{mM} \mathrm{NH}{ }_{4} \mathrm{Ac}-\mathrm{CH}_{3} \mathrm{COOH}(\mathrm{pH}=12)$ at the temperature of $30{ }^{\circ} \mathrm{C}$. 
peatability. In addition, the resulting F-FDP- $\mathrm{ZrO}_{2} / \mathrm{SiO}_{2} \mathrm{SP}$ showed application potential for the chromatographic separation of ginsenosides (as seen in Fig. S11).

\subsubsection{Acid-base stability investigation}

The acid-base stability of the F-FDP- $\mathrm{ZrO}_{2} / \mathrm{SiO}_{2}$ column was evaluated at a pH of 3.0 and 12. As shown in Fig. 8(a), the $k$ of berberine decreases approximately 60\% after 1900 column volumes elution in a basic mobile phase. As shown in Fig. 8(b), the $k$ of benzoic acid decreases by approximately 30\% after 5 days of elution under acidic conditions. The results demonstrated that the SPs endcapped with $\mathrm{F}$ showed proper acid-base stability.

\subsubsection{Analysis of benzoic acid in Sprite}

As shown in Fig. S12, a plot of the peak area (y) against concentration $\left(\mathrm{x}, \mathrm{mg} \mathrm{L}^{-1}\right)$ of benzoic acid standards yields a straight line from 10 to $1000 \mathrm{mg} \mathrm{L}^{-1}$, with a resulting equation of $y=1034.5600 \mathrm{x}-4680.9063\left(\underline{n}=3, \mathrm{R}^{2}=0.9997\right)$. The recovery of benzoic acid in Sprite ranged from 98.10 to $102.12 \%$. A content of $263.01 \mathrm{mg} \mathrm{L}^{-1}$ benzoic acid was detected in the commercial samples of Sprite $(n=3)$. The results showed that the F-FDP- $\mathrm{ZrO}_{2} / \mathrm{SiO}_{2}$ column could be used for the analysis of practical samples.

\section{Conclusion}

A new end-capping reagent $(\mathrm{F})$ was employed to prepare $\mathrm{ZrO}_{2} / \mathrm{SiO}_{2}$ based HILIC SPs. The resulting SPs exhibited better chromatographic performance than the SPs without end-capping. The baseline separation and good peak shape of alkaloids and benzoic acids demonstrated that the end-capping reagent is very valuable for improving the chromatographic performance of SPs. Additionally, the synthesized F-FDP- $\mathrm{ZrO}_{2} / \mathrm{SiO}_{2}$ materials facilitate the analysis of benzoic acid in Sprite and the separation of ginsenosides. Moreover, this modification strategy can be widely applied to the synthesis of metal oxide (e.g., $\mathrm{TiO}_{2}$ or $\mathrm{ZrO}_{2}$ ) based materials having abundant Lewis acid sites. The synthesized SPs have significant potential for solving the problems of the separation and purification of polar pharmaceuticals.

\section{Declaration of Competing Interest}

The authors declare that they have no known competing financial interests or personal relationships that could have appeared to influence the work reported in this paper.

\section{CRediT authorship contribution statement}

Zhihua Song: Methodology, Writing - original draft. Jinhua Li: Writing - review \& editing. Wenhui Lu: Investigation, Writing review \& editing. Bowei Li: Writing - review \& editing. Jinqiu Liu: Visualization. Yaqi Wang: Visualization. Yumeng Wang: Visualization. Zhong Zhang: Writing - review \& editing. Lingxin Chen: Writing - review \& editing.

\section{Acknowledgments}

This work was supported by the Science and Technology Innovation Development Plan of Yantai City of China (2020MSGY112), the National Demonstration Center for Experimental Pharmacy Education (Yantai University), the Natural Science Foundation of Shandong Province (ZR2020QB183), the Taishan Scholar Project Special Funding (ts20190962), Shandong Key Laboratory of Coastal Environmental Processes, YICCAS Grant No. 2019SDHADKFJJ17, the Fundamental Research Fund of the Central University (GK202003089), and the National Natural Science Foundation of China (22008128, 21876199, 41776110, 22176210).

\section{Supplementary materials}

Supplementary material associated with this article can be found, in the online version, at doi:10.1016/j.chroma.2021.462529.

\section{References}

[1] A.S. Kaplitz, G.A. Kresge, B. Selover, L. Horvat, E.G. Franklin, J.M. Godinho, K.M. Grinias, S.W. Foster, J.J. Davis, J.P. Grinias, High-throughput and ultrafast liquid chromatography, Anal. Chem. 92 (2020) 67-84.

[2] H. Yu, G.Q. Yang, M. Sato, T. Yamaguchi, T. Nakano, Y.C. Xi, Antioxidant activities of aqueous extract from stevia rebaudiana stem waste to inhibit fish oil oxidation and identification of its phenolic compounds, Food Chem. 232 (2017) 379-386

[3] G.S. Li, M.L. Yang, X.M. Hao, C.M. Li, Y.L. Gao, J. Tao, Acute toxicity of sodium formononetin-3'-sulphonate (Sul-F) in sprague-dawley rats and beagle dogs, Regul. Toxicol. Pharmacol. 73 (2015) 629-633.

[4] D.Y. Duan, A.P. Wang, L. Ni, L.P. Zhang, X.J. Yan, Y. Jiang, H.J. Mu, Z.M. Wu, K.X. Sun, Y.X. Li, Trastuzumab- and Fab' fragment-modified curcumin PEGPLGA nanoparticles: preparation and evaluation in vitro and in vivo, Int. J. Nanomed. 13 (2018) 1831-1840.

[5] G. D'Orazio, C. Fanali, M. Karchkhadze, B. Chankvetadze, S. Fanali, Enantiomeric separation of some chiral analytes using amylose 3,5-dimethylphenylcarbamate covalently immobilized on silica by nano-liquid chromatography and capillary electrochromatography, J. Chromatogr. A 1520 (2017) 127-134.

[6] D. Cabooter, B. Wuyts, G. Desmet, A. Van Schepdael, F. Lynen, Variable column length method development strategy for amino acid analysis in serum samples of neonates with metabolic disorders, J. Chromatogr. A 1292 (2013) 229-238.

[7] J.P. Ma, G.G. Wu, S. Li, W.Q. Tan, X.Y. Wang, J.H. Li, L.X. Chen, Magnetic solid-phase extraction of heterocyclic pesticides in environmental water samples using metal-organic frameworks coupled to high performance liquid chromatography determination, J. Chromatogr. A 1553 (2018) 57-66.

[8] M. Arabi, A. Ostovan, A.R. Bagheri, X.T. Guo, J.H. Li, J.P. Ma, L.X. Chen, Hydrophilic molecularly imprinted nanospheres for the extraction of rhodamine B followed by HPLC analysis: a green approach and hazardous waste elimination, Talanta 215 (2020) 120933.

[9] F. Yang, C.X. Yang, X.P. Yan, Post-synthetic modification of MIL-101(Cr) with pyridine for high-performance liquid chromatographic separation of tocopherols, Talanta 137 (2015) 136-142.

[10] Y.H. Wang, H. Bu, L. Wang, L.C. Wang, Y. Guo, X.J. Liang, S. Wang, High efficiency and simple preparation of polyacrylamide coated silica stationary phase for hydrophilic interaction liquid chromatography, J. Chromatogr. A 1605 (2019) 360357.

[11] T.P. Cai, H.J. Zhang, J. Chen, Z. Li, H.D. Oiu, Polyethyleneimine-functionalized carbon dots and their precursor co-immobilized on silica for hydrophilic interaction chromatography, J. Chromatogr. A 1597 (2019) 142-148.

[12] K. Qian, Z.Q. Yang, F.F. Zhang, B.C. Yang, P.K. Dasgupta, Low-bleed silica-based stationary phase for hydrophilic interaction liquid chromatography, Anal. Chem. 90 (2018) 8750-8755.

[13] X.J. Liang, S.A. Wang, J.G. Niu, X. Liu, S.X. Jiang, Preparation and ion chromatographic properties of a new core-shell chromatographic support $\mathrm{Al}_{2} \mathrm{O}_{3} / \mathrm{SiO}_{2}-10$, J. Chromatogr. A 1216 (2009) 3054-3058.

[14] C.H. Collins, C.R. Silva, A.M. Faria, K.E. Collins, I.C.S.F. Jardim, The search for more $\mathrm{pH}$ stable stationary phases for high performance liquid chromatography, J. Braz. Chem. Soc. 20 (2009) 604-612.

[15] H.J. Dun, W.Q. Zhang, Y. Wei, X.Q. Song, Y.M. Li, L.R. Chen, Layer-by-layer self-assembly of multilayer zirconia nanoparticles on silica spheres for HPLC packings, Anal. Chem. 76 (2004) 5016-5023.

[16] Z.H. Huang, Q. Wu, H.M. Lu, Y. Wang, Z.M. Zhang, Separation of glycolipids/sphingolipids from glycerophospholipids on $\mathrm{TiO}_{2}$ coating in aprotic solvent for rapid comprehensive lipidomic analysis with liquid microjunction surface sampling-mass spectrometry, Anal. Chem. 92 (2020) 11250-11259.

[17] H.B. He, W.N. Zhang, S.L. Da, Y.Q. Feng, Preparation and characterization of a magnesia-zirconia stationary phase modified with $\beta$-cyclodextrin for reversed-phase high-performance liquid chromatography, Anal. Chim. Acta 513 (2004) 481-492

[18] Q. Wang, Z.Y. Luo, M. Ye, Y.Z. Wang, L. Xu, Z.G. Shi, L.Y. Xu, Preparation, chromatographic evaluation and application of adenosine $5^{\prime}$-monophosphate modified $\mathrm{ZrO}_{2} / \mathrm{SiO}_{2}$ stationary phase in hydrophilic interaction chromatography, J. Chromatogr. A 1383 (2015) 58-69.

[19] J. Nawrocki, M.P. Rigney, A. Mccormick, P.W. Carr, Chemistry of zirconia and its use in chromatography, J. Chromatogr. A 657 (1993) 229-282.

[20] H.B. He, Y.Q. Feng, Q. Li, S.L. Da, Z.X. Hu, Preparation and evaluation of n-octadecylphosphonic acid-modified magnesia-zirconia stationary phases for reversed-phase liquid chromatography, Anal. Chim. Acta 542 (2005) 268-279.

[21] H.B. He, Y.F. Feng, S.L. Da, Z.H. Wang, An investigation on the cation-exchange and Lewis-base interactions of a n-octadecylphosphonic acid-modified magnesia-zirconia stationary phase, Anal. Chim. Acta 551 (2005) 213-221.

[22] Z.H. Song, S.H. Li, Y.F. Guan, S. Wang, Y.H. Wang, G.Q. Yang, X.C. Zhang, J.H. Li W.H. Song, C.M. Zhou, L.X. Chen, Facile synthesis of zirconia-coated mesoporous silica particles by hydrothermal strategy under low potential of hydrogen conditions and functionalization with dodecylphosphonic acid for high-performance liquid chromatography, J. Chromatogr. A 1612 (2020) 460659. 
[23] G. Crescentini, F. Bruner, F. Mangani, Y.F. Guan, Preparation and evaluation of dry-packed capillary columns for high performance liquid chromatography, Anal. Chem. 60 (1988) 1659-1662.

[24] Z.X. Huo, Q.H. Wan, L. Chen, Synthesis and evaluation of porous polymethylsilsesquioxane microspheres as low silanol activity chromatographic stationary phase for basic compound separation, J. Chromatogr. A 1553 (2018) 90-100.

[25] N. Wang, J. Zhang, Q. Li, H. Xu, G. Chen, Z.Y. Li, D.F. Liu, X. Yang, Discovery of potent indoleamine 2,3-dioxygenase (IDO) inhibitor from alkaloids in picrasma quassioides by virtual screening and in vitro evaluation, Fitoterapia 133 (2019) 137-145.

[26] L.G. Yang, G. Wang, M. Wang, H.M. Jiang, L.X. Chen, F. Zhao, F. Qiu, Indole alkaloids from the roots of isatis indigotica and their inhibitory effects on nitric oxide production, Fitoterapia 95 (2014) 175-181.
[27] P. Jandera, P. Janas, Recent advances in stationary phases and understanding of retention in hydrophilic interaction chromatography. a review, Anal. Chim. Acta 967 (2017) 12-32.

[28] J.C Q. Wang, K. Huang, X. Zhang, L. Xu, Z.G. Shi, Preparation, characterization and application of N-methylene phosphonic acid chitosan grafted magnesia-zirconia stationary phase, Anal. Chim. Acta 854 (2015) 191-201.

[29] T. Fujiyoshi, T. Ikami, K. Kikukawa, M. Kobayashi, R. Takai, D. Kozaki, A. Yamamoto, Direct quantitation of the preservatives benzoic and sorbic acid in processed foods using derivative spectrophotometry combined with micro dialysis, Food Chem. 240 (2018) 386-390.

[30] Q. Wang, J. Li, X. Yang, L. Xu, Z.G. Shi, L.Y. Xu, Investigation on performance of zirconia and magnesia-zirconia stationary phases in hydrophilic interaction chromatography, Talanta 129 (2014) 438-447. 